\title{
Erratum to: Toxico-/biokinetics of nanomaterials
}

\author{
Robert Landsiedel • Eric Fabian • Lan Ma-Hock • \\ Ben van Ravenzwaay • Wendel Wohlleben • \\ Karin Wiench · Franz Oesch
}

Published online: 3 July 2012

(C) Springer-Verlag 2012

\section{Erratum to: Arch Toxicol}

DOI 10.1007/s00204-012-0858-7

Unfortunately, there has been a mistake concerning the order of the authors in the original publication. It is now corrected here.

The online version of the original article can be found under doi:10.1007/s00204-012-0858-7.

R. Landsiedel - E. Fabian - L. Ma-Hock - B. van Ravenzwaay ·

W. Wohlleben $\cdot$ K. Wiench

Department of Experimental Toxicology and Ecology,

BASF SE, 67056 Ludwigshafen, Germany

W. Wohlleben

Department of Polymer Physics, BASF SE,

67056 Ludwigshafen, Germany

\section{K. Wiench}

Department of Product Safety, BASF SE,

67056 Ludwigshafen, Germany

F. Oesch

Institute of Toxicology, University of Mainz,

55131 Mainz, Germany

F. Oesch $(\square)$

Rheinblick 21, 55263 Wackernheim, Germany

e-mail: oesch@uni-mainz.de 